\title{
Testicular neuroblastoma
}

\author{
G. Rispoli $\cdot$ E. Eshja $\cdot$ P. F. Felisaz
}

Received: 25 January 2013/ Accepted: 30 January 2013/Published online: 7 May 2013

(C) Società Italiana di Ultrasonologia in Medicina e Biologia (SIUMB) 2013

\begin{abstract}
We report a case of isolated intratesticular neuroblastoma in a 17-year-old boy with a history of recurrent metastatic neuroblastoma. He had undergone multiple cycles of chemotherapy, and at the time of our examination was apparently disease-free. Testicular metastases are not uncommon in patients with active metastatic neuroblastoma, but isolated testicular involvement is rare. In this case, ultrasound follow-up allowed early diagnosis and prompt treatment of the testicular lesion. At the 18-month follow-up visit, the patient remains disease-free.
\end{abstract}

\section{Keywords Neuroblastoma $\cdot$ Testis · Ultrasound}

Riassunto Riportiamo il caso di localizzazione testicolare di neuroblastoma in un ragazzo di 17 anni, affetto precedentemente da una forma diffusa della stessa patologia, già recidivata e sottoposta a multipli trattamenti. Le metastasi testicolari da neuroblastoma possono comparire negli stadi più avanzati di malattia, ma localizzazioni testicolari isolate sono rarissime. Nel nostro caso il follow-up con ecografia ha permesso una diagnosi precoce di localizzazione e la messa in atto di un trattamento efficace. Il ragazzo prosegue il follow-up ed è da 18 mesi libero da malattia.

G. Rispoli

Servizio di Radiodiagnostica, Policlinico San Matteo,

Pavia, Italy

E. Eshja · P. F. Felisaz $(\square)$

Istituto di Radiologia, Policlinico San Matteo,

Università di Pavia, Pavia, Italy

e-mail: paulfel@hotmail.it

\section{Introduction}

Neuroblastoma, the most common extracranial tumor in childhood, is considered an embryonic malignancy that arises from the persistence of immature cells from the neural crest. The tumor can develop during the embryonic or postnatal period in any tissue that originates from the neural crest, including the adrenal medulla (35\%), paravertebral ganglia (30-35\%), posterior mediastinum (20\%), head-neck district (1-5\%), and pelvis (2-3\%); less frequent locations are the thymus, lung, kidney, anterior mediastinum, and cauda equina $[1,2]$. Scrotal, testicular, and paratesticular involvement is rare. Approximately, 30 cases of testicular or paratesticular neuroblastoma have been reported in children, and most cases represent metastases from an adrenal neuroblastoma [3]. We report a rare case of isolated intratesticular neuroblastoma in a young boy.

\section{Case report}

A 17-year-old boy was referred to our staff for a testicular ultrasound for the assessment of secondary hypogonadism. At the age of 4 years, the boy had developed a neuroblastoma (stage IV, N-Myc amplification) in the cervicolateral region with massive bone marrow involvement. The cancer had been treated with a single cycle of chemotherapy (AIEOP [Associazione Italiana Ematologia Oncologia Pediatrica] 97 Protocol, stage IV), which produced complete remission. When he was 12 years old, the disease recurred with bone marrow, lymph node, and skeletal involvement, which was treated with a cycle of chemotherapy (AA 01 NB Protocol). Complete remission of the disease was again achieved, and the patient received a bone 
marrow transplant from an HLA-identical donor. For the next 5 years, he remained disease-free and in good health with the exception of mild chemotherapy-induced hypogonadism, which was being treated with steroid replacement therapy.

The ultrasound study revealed a solid nodule measuring approximately $20 \times 21 \mathrm{~mm}$ in the lower third of the left testis. The mass, which was hypoechoic (Fig. 1a) with well-defined margins, an inhomogeneous echo structure, and evidence of hypervascularization (Fig. 1b), was strongly suspected to be neoplastic, and surgical biopsy was performed. The lesion proved to be not a primary testicular tumor but a new neuroblastoma. Left orchiectomy was performed with insertion of an intrascrotal implant. Histopathological examination of the surgical specimen confirmed the diagnosis of intratesticular neuroblastoma. Total body computed tomography was performed for restaging purposes. It revealed several hypervascularized focal hepatic lesions, which were subsequently diagnosed as benign (multiple focal nodular hyperplasia, FNH) on the basis of magnetic resonance imaging studies. No other sites of disease involvement were reported. Given the history of multiple recurrence, the boy underwent an additional cycle of chemotherapy. He has been followed for 18 months and is currently diseasefree. A second MRI shows no change in the liver lesions, which confirms their benign nature.

\section{Discussion and conclusions}

Our review of the literature reveals reports of nine cases of primary paratesticular neuroblastoma [4] and only one case of isolated primary intratesticular neuroblastoma, and in the latter case the patient developed diffuse disease a few months after the testicular lesion was diagnosed [5]. All other patients with testicular neuroblastoma had advanced infradiaphragmatic disease [6].

Simon et al. [2] attempted to explain the pathogenesis of testicular neuroblastoma. The first hypothesis attributes the tumors to the persistence in paratesticular tissues or in the testis itself of ectopic paraganglionic cells. These cells are found in various regions of the fetal body during intrauterine life, but they normally regress within the second year of life. Another more plausible hypothesis attributes the development of intrascrotal neuroblastoma to secondary dissemination of a retroperitoneal neuroblastoma, presumably via the lymphatic system. Most of the cases reported thus far tend to support this hypothesis, and our own is probably no exception.

Ultrasonography is confirmed as the first-line method for the study of the testis and for identifying these tumors, which present as a mass with an inhomogeneous
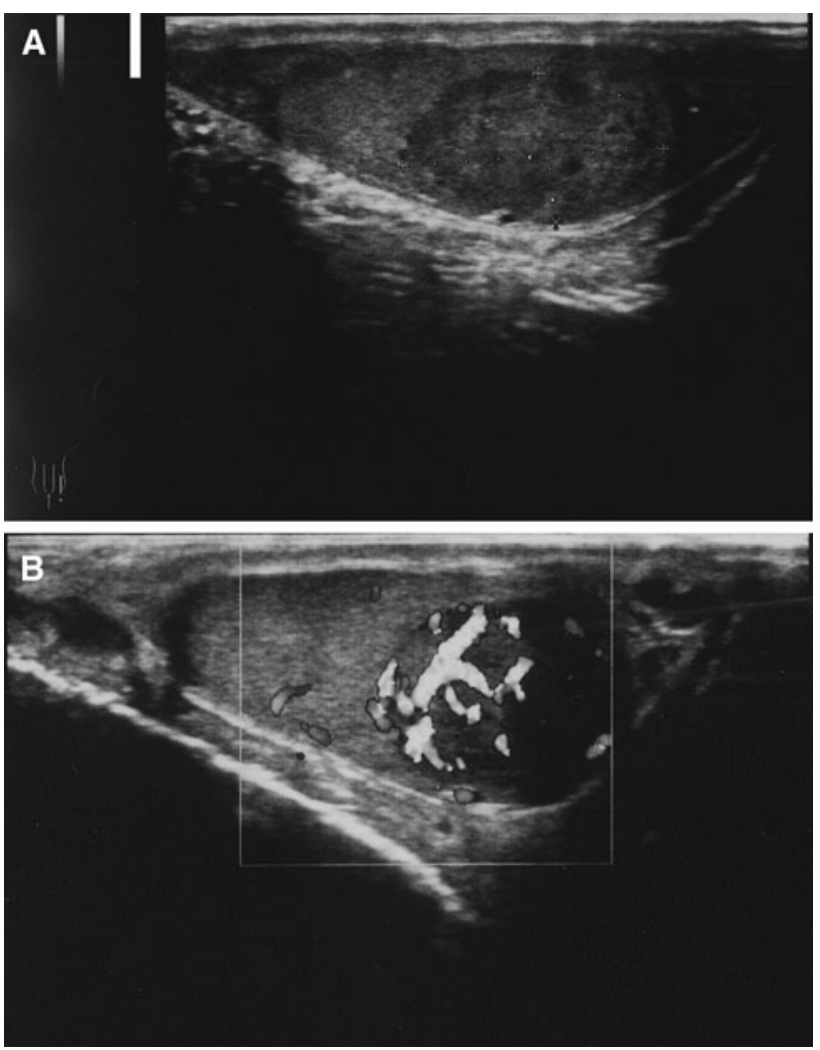

Fig. 1 Sonographic image of the left testicle: the B-mode examination reveals a roundish, inhomogeneously hypoechoic lesion measuring $12 \times 20 \mathrm{~mm}$ (a). Color Doppler documents the hypervascularity of the lesion (b)

echostructure (Fig. 1a) containing areas of necrosis and calcification. As for other imaging methods, computed tomography plays a crucial role in the detection of metastatic spread, lymph node involvement, and calcifications. Magnetic resonance imaging is the method of choice for evaluating tumor extension at the level of the spinal cord. It is also valuable for monitoring FNH-like hepatic lesions, which are frequently found in patients like ours, who have received multiple cycles of chemotherapy. In all cases, the diagnosis must be confirmed by histological examination.

Conflict of interest None.

\section{References}

1. Alessi S, Grignani M, Carone L (2011) Ganglioneuroblastoma: case report and review of the literature. J Ultrasound 14:84-88

2. Simon T, Hero B, Berthold F (2000) Testicular and paratesticular involvement by metastatic neuroblastoma. Cancer 88(11): 2636-2641

3. Hua X, Mao-Sheng X, Hong-Quan G, Fang C (2008) Primary paratesticular neuroblastoma: a case report and review of literature. J Pediatr Surg 43(11):e5-e7 
4. Berger M, Hurtado MF, Bertolez SP, Fernandez-Pineda I (2012) Primary paratesticular neuroblastoma: An important differential diagnosis. J Pediatr Urol. pii: S1477-5131(12)00250-1

5. Kellie SJ, Waters KD (1985) Testicular neuroblastoma. J Surg Oncol 29(3):201-204

6. Gallagher BL, Vibhakar R, Kao S, Cooper CS (2006) Bilateral testicular masses: an unusual presentation of neuroblastoma. Urology 68(3):672.e15-672.e17 